composition of skin, pointing out that, although collagen is the principal constituent, the remaining substances may have an important influence on the conversion of collagen to gelatin as well as on the tanning properties of the skin. Elastin fibres, reticular tissue, keratin, muscle fibres, sweat and sebaceous glands all occur, and, in addition, polysaccharides are present in small amounts.

Turning to the composition of collagen, Dr. Bowes reviewed the work which she, together with Prof. A. C. Chibnall and his collaborators, have done on the amino-acid composition of collagen. The collagen was specially prepared with minimum modification of the skin used. The results showed that almost the entire amino-acid composition is accounted for, and that cystine and tryptophan are absent. Dr. Bowes pointed out the relation between the titration curve obtained with collagen and its composition, and considered the modifications which occur when collagen is treated with alkali for prolonged periods. The most important reaction is the hydrolysis of the amide groups, with the production of ammonia. In addition, the swelling of collagen under alkaline conditions cannot be adequately interpreted unless a loss of cohesion is postulated. A lively discussion followed the paper.

The afternoon session consisted of a paper by the director of research of the Association, Mr. A. G. Ward, on "Recent Studies of High Polymers in Relation to the Properties of Gelatine and Glue". Mr. Ward described the methods which have enabled quantitative data to be obtained for high polymers. The importance of the non-uniformity of the molecular weight of gelatin was stressed, and the signi. ficance of the various forms of average molecular weight was discussed. Experimental methods were described which have been successfully applied to gelatin, including osmotic pressure, surface pressure and the ultracentrifuge. Further aspects of high polymers which were outlined were the theory of degradation of polymer chains and the origin of rubber-like elasticity. Results already obtained for gelatin by such workers as Scathard, Pouradier and Ferry were described.

\section{CHEMISTRY AT UNIVERSITY COLLEGE, DUNDEE}

$\mathrm{D}$ URING the past three years the Chemistry Department of University College, Dundee, has been enlarged, renovated and re-equipped. On October 23 the new building was formally opened by Lord Burghley, rector of the University of St. Andrews. Sir James Irvine, vice-chancellor and principal of the University of St. Andrews, introduced Prof. N. V. Sidgwick, formerly professor of chemistry in the University of Oxford, who delivered an address. After the ceremony, Lady Burghley laid the foundation stone of a new science building which will house the Department of Electrical Engineering and the Department of Botany at Dundee.

The original chemistry laboratory at Dundee was built in 1883. It followed the German nineteenthcentury style, having been modelled, like those of the Imperial College of Science and Technology, London, and of Owens College, Manchester, on Hofmann's laboratory at Bonn. At that time the Dundee laboratory ranked among the best-equipped in Great Britain, and was unique in -its air-conditioning system which had been designed by Thomas Carnelley, the first professor at Dundee, along lines which have now become standard engineering practice. The building was added to in 1888 , and the original plan was completed in 1905 . Apart from some internal renovation in 1925, the Department has remained largely unchanged for nearly fifty years.

A storey has now been added, and the whole building has been completely renovated and reserviced. The new floor provides two teaching laboratories, four organic chemistry research rooms and a glassblowers' workshop. The basement rooms vacated by the organic chemists have been converted to physical chemistry research laboratories. The two new teaching laboratories are each designed to accommodate thirty-two students comfortably ; one will be used for teaching organic chemistry to secondand third-year students, while the other is shared between inorganic and physical chemistry teaching at the same level. The servicing of the building has been renewed and now includes all the usual piped services (gas, hot and cold water, compressed air and live steam) with a selection of electrical services (415 V. three-phase A.C., 240 V. A.c., 240 V. D.c. and $50 \mathrm{~V}$. D.c.). The building is steam-heated and airconditioned throughout.

In addition to the rebuilding, the Department has been extensively re-equipped. The research facilities have been extended to cover most important modern techniques in both physical and organic chemistry with the object of enabling problems to be studied using several different experimental methods. The work of the laboratory is at present concentrated mainly on the thermodynamics of solutions and adsorbed phases, electrochemistry, free-radical reactions and their relevance in polymer chemistry, acid-base catalysis, stereochemistry and problems of optical activity, together with general problems of reactivity of organic molecules. Furthermore, a full range of optical and spectroscopic techniques will shortly be available to supplement purely thermodynamic messurements. A well-equipped workshop and glassblowers' shop are making important contributions to these developments. It can now be fairly claimed that University College, Dundee, has a Chemistry Department which, for its size, is again among the best-equipped in Great Britain.

A conversazione was held on the afternoon of October 23, followed by the formal opening. Visitors were able to see a variety of research work in progress, demonstrations of the experiments used in the teaching laboratories, and a series of lecture demonstration models. Lord Burghley and the other guests, including representatives of Scottish universities and chemical industry, and past students, were welcomed by Prof. D. H. Everett, who referred to the difficulties which had been overcome in carrying through the reconstruction while the laboratory was in full use for both teaching and research. In a few words Lord Burghley declared the renovated building open.

Prof. Sidgwick began his address by mentioning the past holders of the chair of chemistry in University College, Dundee, since the foundation of the chair in 1882. Thomas Carnelley was professor for only six years and would, had he lived, have risen to a very high position in science. Percy Faraday Frankland, who in the field of chemistry was the distinguished son of an even more distinguished father, held the chair in Dundee during 1888-94; he then moved to Birmingham-and, incidentally, built there a labor- 
atory closely resembling the one he left behind. He was followed by James Walker, much of whose best scientific work was done in Dundee before he moved to Edinburgh in 1908. Hugh Marshall's tenure of the chair was eut short by his untimely death in 1913 . Alexander McKenzie, whose contributions to stereochemistry gained him world-wide reputation, wes professor in Dundee during 1914-38. He was followed by W. F. K. Wynne-Jones (1938-47) and later by the present holder, Prof. Everett.

The increased facilities in Dundee for the teaching of chemistry and for research should benefit three classes of the community: the students in general, the research workers ard chemical in:dustry. Referring to the first group, Prof. Sidgwick stressed the purely educational value of chemistry and also the importance of teaching it as an experimental subject. Compared with the very simple apparatus available in his youth, that in use to-day might seem elaborate; but Prof. Sidgwick commented that, although really good men got valuable results with very limited accommodation, their work would havo been still better had they had more space and better equipment. Modern techniques have opened up new fields of investigation which must be available to our students if they are not to be seriously handicapped in their research.

The relationship between universities and chemical industry was dealt with by Prof. Sidgwick in some detail. Up to the end of the past century the great majority of chemical manufacturers did not believe that science could help them ; to-day almost every chemical firm has a research department. It is therefore of the greatest importance that adequate numbers of trained chemists should be provided by universities; but Prof. Sidgwick was apprehensive of the danger that, by offering large salarits, industry might now attract away many of the best research students and teachers and so cut down the supply of trained scientific workers.

On the closer link between industry and the universities, Prof. Sidgwick commented on the much more liberal attitude now adopted by an increasing number of firms. Money is now often given to laboratories and research students without restriction on the research problems to be engaged upon, and with complete freedom of publication. This is most satisfactory, but a difficult problem still remains in connexion with consultant work carried out by members of university staffs. While agreeing that this is beneficial both to methods of production and to the consultant's pocket, Prof. Sidgwick feared that it might also interfere with the teaching and research activities in the university. There seems to be no general solution of this problem, which is clearly one which has to be treated in each case individually.

D. H. EVERETT

\section{MEMBRANE PERMEABILITY}

A

$T$ the annual meeting of the Society of Leather Trades' Chemists, held during September 22-23 in the University of Leeds, the fourth Procter Memorial Lecture was delivered by Prof. E. K. Rideal, who chose as his subject "Membrane Permeability". Prof. Rideal, professor of chemistry in King's College, London, began by reminding his audience that natural membranes of animal origin contain proteins and lipoids; the bacteria contain mucoids and magnesium ribonucleate; and the plants, cellulose. The physiologist attempts to explore the nature of natural membranes in vivo, while the physico-chemical approach is to make models and find which one behaves most naturally. The monolayer technique reveals that membranes behaving as osmotic barriers must be multimolecular in thickness.

Three different types of membranes are recognized : the so-called sieve or capillary membrane, the lipoid or oil membrane, and the membrane consisting of a polymer. The problem of permeability has been attacked by direct passage, by osmotic and by E.M.F. methods. Each has contributed some information of value. Capillary membranes may consist of relatively large pores, as in aggregations of particles of different sizes ; of laminar sheets, as in charcoal; or even of molecular pores, as in the zeolites.

The interest of the investigator is in tube areas and lengths, the latter involving a tortuosity factor. The Kozeny-Carman treatment of void fraction and surface area neglects in vapours the surface flow along the capillaries. In liquid flow, application of the Kelvin equation leads to the assumption of an immobile adsorbed layer of liquid. The work of Michaelis on the E.M.F. across sieve membranes has been reinterpreted by Meyer and Teorell in terms of two Donnan restraints on each side of the membrane and a number of fixed charges inside the membrane.

The permeability constant $P$, that is, the number of c.c. at N.P.T. of gas passing in 1 sec. through $1 \mathrm{sq} . \mathrm{cm}$. of thickness $1 \mathrm{~mm}$., is the product of the diffusion constant $D$ and the solubility constant $S$. The former may vary as the membrane concentration of dissolved vapour changes. The permeability of polymer membranes is determined by the number of Eyring holes in the membrane capable of holding molecules of the penetrant, and the movement through the membrane is determined by the microBrownian movement of the non-crystalline chain segments of the polymer. Movement is thus a property of the polymer; the permeation process requires an energy of activation and is not a free diffusion; solute molecules suffer a large change in entropy when 'dissolved' in a polymer, that is, they are rather tightly held. The micro-Brownian movement of the chain segments likewise involves consideration of the ratio of fringe to micelle in the 'fringed micelle' type of polymer. Some penetrants can peptize the micelles; others cannot do so. If such a polymer membrane is expanded by solvent or plasticizer, it passes over into the capillary-type, which has already been discussed.

The oil type of membrane seems to bear the closest analogy to natural membranes, which may consist of a lipoid-like material held in an open network of cellulose, or in the form of a lipoid lipo-protein complex mosaic. The reactions at the interface between the membrane boundaries and the homogeneous phases can be studied by the monolayer technique; here the control of the mechanism of chemical reactions by surface tension changes, as well as the phenomenon of penetration, are allimportant. While the electrometric work of Beutner and his colleagues represents, in the main, nonequilibrium conditions, it is important to study the rate of transfer of solute across the boundaries by direct as well as electrochemical means. The data obtained in this way bear a close resemblance to those natural cell walls which have been investigated. 